\title{
Co-Th (Cobalt-Thorium)
}

\section{H. Okamoto}

The Co-Th phase diagram in [Massalski2] was drawn by [1990Ish]. [2008Wan] attempted to reproduce this phase diagram by thermodynamic modeling. The result is shown in Fig. 1. The shape of the liquidus around the congruent melting point of $\mathrm{Co}_{17} \mathrm{Th}_{2}$ was extremely asymmetric in the diagram of [1990Ish]. This unlikely situation was resolved in the phase diagram of [2008Wan] by raising the $\mathrm{L} \rightarrow$ $\mathrm{Co}_{17} \mathrm{Th}_{2}+\mathrm{Co}_{5} \mathrm{Th}$ eutectic temperature from 1300 to $1424{ }^{\circ} \mathrm{C}$. Except this substantial modification, the phase diagram of [1990Ish] was well reproduced in the phase diagram of [2008Wan].

\section{References}

1990Ish: K. Ishida, T. Nishizawa, and H. Okamoto, Co-Th (Cobalt-Thorium) in [Massalski2]

2008Wan: C.P. Wang, P. Yu, X.J. Liu, I. Ohnuma, R. Kainuma, and K. Ishida, Thermodynamic Assessment of the Co-Th and Fe-Th Systems, J. Alloys Compd., 2008, 457, p 150-156

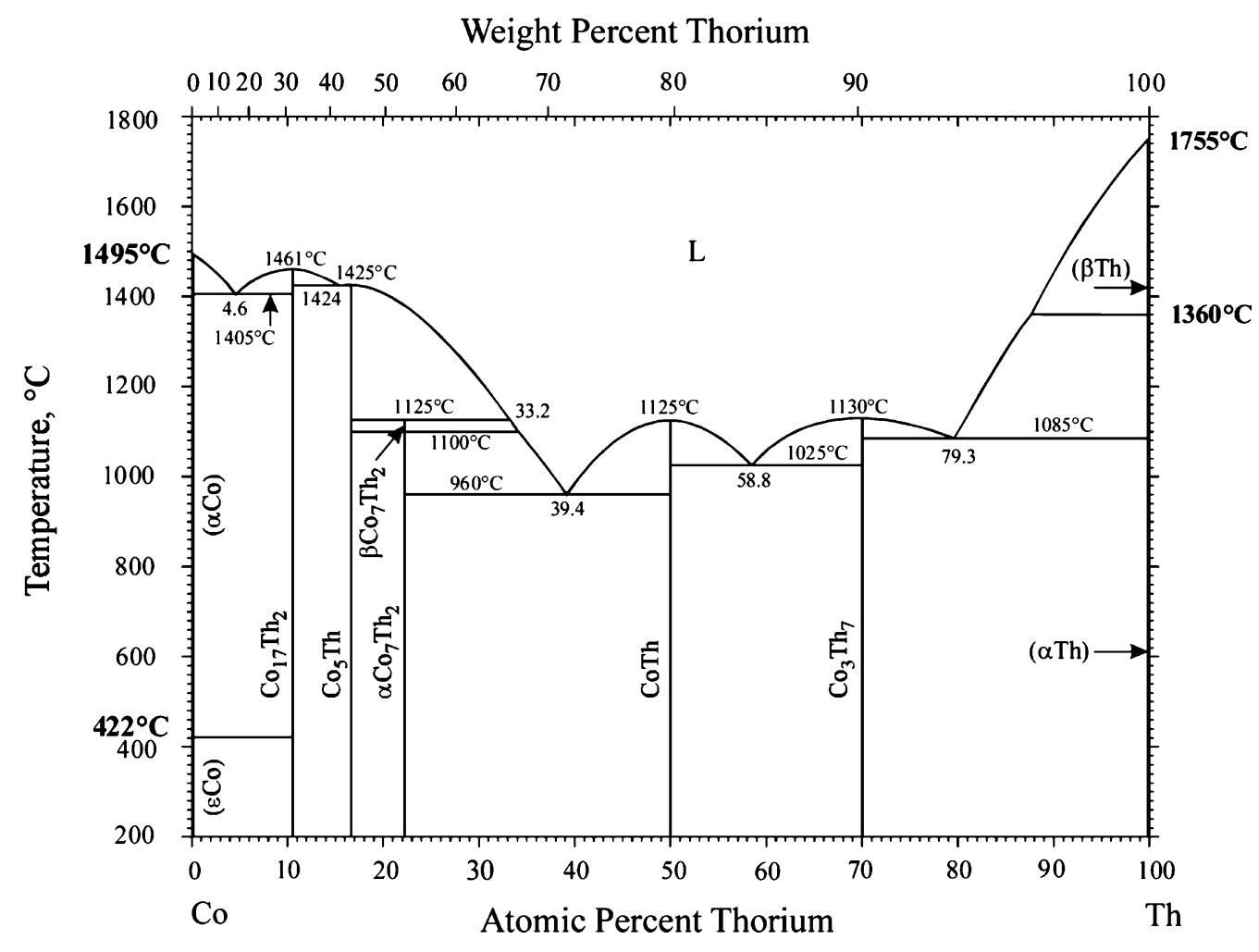

Fig. 1 Co-Th phase diagram 